\title{
Assessment of External Economic Cooperation in the Aspect of Transport Development of the Greater Tumen Initiative
}

\author{
Sergei Vakulenko ${ }^{1}$,Evgeniy Nekhoroshkov ${ }^{2}$, Peter Majercak ${ }^{3 *}$ Mikhail Karyshev ${ }^{4}$ \\ ${ }^{1}$ Russian University of Transport (RUT-MIIT), Moscow, Russia. Email:post-iuit@bk.ru \\ 2 Siberian State Transport University, Novosibirsk, Russia \\ ${ }^{3}$ University of Zilina, Faculty of Operation and Economics of Transport and Communications, \\ Univerzitna 1, 01026 Zilina, Slovakia \\ ${ }^{4}$ Samara State University of Railway Transport, Samara, Russia Karyshev63rus@gmail.com
}

\begin{abstract}
Research background: The aim of the scientific contribution is to analyze the aspect of Transport Development of the Greater Tumen Initiative. Economic cooperation among the countries of the Greater Tumen Initiative (GTI) is the basis for interaction in various fields, especially transport.

Purpose of the article: However, taking into account the prevailing trends in Europe-Asia transportation, it is not entirely correct to make the implementation of GTI transport projects dependent on prospective transit freight flows. At first, it is necessary to concentrate on the transport support of foreign trade flows directly between the GTI member countries.

Methods: We propose to assess the stability of foreign trade flows as a cargo base (current and potential) of transport projects within the GTI by absolute time series, which reflects the trend (or its absence, i.e. each next level is higher or lower than the previous one) and its stability, as well as by relative time series, i.e. growth rates, which reflects the stability of the change rate (the growth rate of each subsequent period is higher or lower than the previous one).

Findings \& Value added: Based on the results of the assessment of foreign trade flows between the member countries, that forms the current and potential cargo base of transport projects, it was concluded not only about a high degree of stability and potential of foreign economic cooperation, but also about the need of extra measures for its further intensifying, including foreign trade transport services improvement.
\end{abstract}

Keywords: Tumen; transport; logistics performance; transport modes

JEL Classification: $J 54$; $J 55 ; J 64$

\footnotetext{
* Corresponding author: peter.majercak@fpedas.uniza.sk
} 


\section{Introduction}

The Greater Tumen Initiative (GTI) is an intergovernmental system of cooperation between four countries - China, Mongolia, the Republic of Korea, and the Russian Federation in Northeast Asia (the Democratic People's Republic of Korea was a member of the GTI until 2009). The governments of the GTI member countries have pledged to strengthen economic cooperation and promote sustainable development and growth in Northeast Asia and especially in the Greater Tumen region, including Chinese northeastern provinces - Jilin, Heilongjiang and Liaoning, and Inner Mongolia, along with eastern provinces of Mongolia, eastern port cities of the Republic of Korea, and Primorsky Krai of Russia.

Starting with the "Tumen" program and ending up with the GTI - the initiative develop the Tumen region has been existing for over 25 years and still does not lose its relevance for its member countries as well as for the entire Northeast Asia. It is interesting that most of the studies focused on the development of these countries do not consider the problems and prospects of their participation in the GTI.

For example, studies on the economic development of China as the GTI member country are devoted to a variety of aspects - from finding determinants and development problems to building specific models. Thus, the work of $\mathrm{Lu}$ et al (2020), He et al (2020) both are forecasting the impact of financial development and trade on the entire Chinese economy and building a model of its growth and at the same time devotes the impact of rising trade costs on the economic transformation, which is an important political practice for China's economic development. Among the studies for People's Republic of China there should be Fleisher and Zhang (2021) review highlighted, that provides detailed data for the Chinese economy for over 30 years. The economic development of the Republic of Korea as another member of the GTI is studied, for example, from the standpoint of the comparative advantages manifested in international trade, which is discussed in the study by Sim and Yoo (2018), shocks of foreign and domestic economic policy, the impact of which is studied by Cheng (2017), integration processes that are studied by Lim and Breuer (2019). Chu et al (2020) study the development of another GTI member country - Mongolia. They have attempted to identify the determinants of growth for Mongolia, counting on the impact of its large neighbor-China. Among studies on the economic development of the entire Northeast Asia the study of Thorbecke (2019) should be highlighted, that analysis the characteristics of East Asian products and services values chains and their dependance of various factors. The economic development of Russia is studied in several papers, among those Voskoboynikov (2017) article is worth noting where the author tried to find sources of long-term economic growth. Mitsek (2018) provides the similar study and presents Russian economy econometric model, that enables retrospective and predictive analysis of economy dynamics. In addition, such authors as Ono (2017), who devoted his paper to establish the link between the financial crisis and economic growth in Russia, and Bayramov et al (2020), who studied the mediumterm impact of economic sanctions on development not only in Russia, but also within the countries of the ex-USSR.

This review proves that the GTI member countries are one of the most interesting and relevant research objects, various economic issues of their growth and development hold leading places in the practice of research activities (Majercak, P., Kliestik, T. et.al., 2013). The total gross domestic product (GDP) of the GTI member countries is more than $20 \%$ of the global value with the unconditional leadership of China and three out of four countries (China, the Republic of Korea, Russia) are among the world's key exporters with a combined share of more than $18 \%$. Undoubtedly, these facts confirm the potential possibilities of the 
integration interaction of these countries for the transformation of the GTI into a full-fledged intergovernmental organization.

One of the key objectives of GTI is to promote the development of transport infrastructure. To achieve this goal the Transport Council was created, whose activities are aimed at improving transportation within the GTI and identifying the necessary steps for the development of transport corridors. The member countries agreed that the transport network should be considered as the main priority of cooperation, and it has to be focused on the key regional transport corridors development and construction to connect the main ports, railways, and highways within the Greater Tumen area.

The transport aspect in the context of the development of the GTI member countries is considered in Magazzino and Mele (2020) paper, where the author attempted to find the relationship between transport infrastructure and the economic growth of China, and Foo et al. (2019), who studied the impact of China's Belt and Road Initiative on international trade. It should be noted that the most common object of research on the transport subject of the GTI member countries is the Belt and Road megaproject, which, in accordance with its transit function, can also have a significant impact on the implementation of GTI transport projects. For example, it is quite realistic to connect Russia's initiatives to develop transport corridors, considering its interests in the GTI, with the concepts of the Silk Road Economic Belt and the 21st Century Maritime Silk Road. Lall and Lebrand (2020) tried to understand the spatial effect of the Belt and Road Initiative and its differentiation, implications for the whole of Central Asia. Note that the relationship between transport projects and foreign trade flows was also considered by the authors of this paper - Nekhoroshkov et al (2021).

In general, despite its obvious relevance, the development of China, the Republic of Korea, Mongolia, and Russia and their integration interaction within the GTI are not fully reflected in the above research activities. At the same time, counting on the fundamental importance of the transport aspect of GTI interaction, one of the most vital issues is the assessment of foreign trade flows between the participating countries, those are representing the current and potential cargo base of transport projects. The first important step is the identification of specific areas for transport corridors development and the implementation of prioritized projects for them. Every project should be focused on reducing the influence of border barriers and the transport infrastructure improvement in order to meet the demands of regional economic integration, enabling the sustainability and expediency of foreign economic cooperation between the GTI member countries. The purpose of this paper is to assess foreign trade flows between GTI member countries and to define a cargo base for transport and logistics infrastructure projects development for the entire Greater Tumen region.

\section{Materials and Methods}

It is proposed to assess the foreign trade flows of the GTI member countries as a current and potential cargo base for transport projects by two key points - stability and complementarity, that will reflect the real state in current conditions and prospects for the development of foreign economic cooperation within the GTI.

We propose to assess the stability of foreign trade flows as a cargo base (current and potential) of transport projects within the GTI by absolute time series, which reflects the trend (or its absence, i.e. each next level is higher or lower than the previous one) and its stability, as well as by relative time series, i.e. growth rates, which reflects the stability of the change rate (the growth rate of each subsequent period is higher or lower than the previous one). For 
this, it is necessary to take the formula for calculating the Spearman coefficient (SC) as a basis:

$$
S C=\frac{12 \times \sum_{i=1}^{n} M_{i}}{n^{3}-n}-\frac{3 \times(n+1)}{n-1}
$$

where $S C$ - stability of the trend/rate of foreign trade cooperation;

$M_{i}$ - product of numbers of time periods and their corresponding ranks of absolute/relative values of export/import;

$n$ - duration of observation period.

The coefficient belongs to the range $[-1 ;+1]$ and has the following quality characteristics: less than 0.2 - instability; $[0.2 ; 0.4]$ - weak stability; $[0.4 ; 0.6]$ - average stability; greater than 0.6 - high stability.

This assessment, by comparing the stability of absolute and relative indicators, will significantly reveal the areas of changes in the dynamics of cooperation between the GTI member countries.

Based on the assessment and analysis of the foreign trade cooperation dynamics stability within the GTI areas, it seems possible to identify emerging crisis phenomena and zones of its safe development. In accordance with the level of stability and dynamics trend direction for absolute indicators of exports and imports, along with the stability of the slowdown or increase in the rate of change, points are awarded for each pair of GTI member countries, reflecting the strength of the crisis state sign (signal) (Table 1).

Table 1. A set of signals about crisis phenomena in foreign trade cooperation of the GTI countries

\begin{tabular}{|c|c|c|c|c|c|c|c|}
\hline \multirow{3}{*}{ Stability of the rate } & & \multicolumn{6}{|c|}{ Stability of the trend } \\
\hline & & \multicolumn{2}{|c|}{ weak stability } & \multicolumn{2}{|c|}{ medium stability } & \multicolumn{2}{|c|}{ high stability } \\
\hline & & + & - & + & - & + & - \\
\hline \multirow{2}{*}{ weak stability } & + & 0 & 3 & 0 & 3 & 0 & 4 \\
\hline & - & 2 & 3 & 1 & 3 & 0 & 5 \\
\hline \multirow{2}{*}{ medium stability } & + & 0 & 3 & 0 & 3 & 0 & 4 \\
\hline & - & 2 & 4 & 1 & 4 & 0 & 5 \\
\hline \multirow{2}{*}{ high stability } & + & 0 & 3 & 0 & 3 & 0 & 4 \\
\hline & - & 3 & 4 & 2 & 4 & 1 & 5 \\
\hline
\end{tabular}

Source: Bayramov (2020)

After assigning points for the areas of foreign trade flows within the GTI, it is necessary to calculate the indicator of true conditions, i.e. the number of areas with a signal strength from 1 to 5 , and an indicator of the total signal strength. These indicators are used to calculate the scale and intensity of the signals. The scale reflects the breadth of crisis coverage of foreign trade cooperation within the GTI:

$$
M=\frac{S}{\sum_{j=1}^{m} n_{j}} \times 100 \%
$$

where $M$ - integral signal scale indicator;

$S$ - true signal condition indicator;

$n_{j}-$ total number of areas of foreign trade cooperation. 
The intensity reflects the depth of crisis coverage of foreign trade cooperation within the GTI:

$$
I=\frac{F}{\sum_{j=1}^{m} n_{j} \times r} \times 100 \%
$$

where $I$ - integral indicator of signal intensity;

$F$ - indicator of cumulative signal strength

$n_{j}$ - total number of areas of foreign trade cooperation;

$r$-dimension of the scale of the numerical values of signals.

Using the indicators of the scale and intensity of signals, it seems possible to recognize the stages of crisis phenomena in foreign trade cooperation in key areas of the GTI, that forms the basis of the potential transport congestion within its framework. A visual representation for the possible results interpretation is presented in Table 2.

The potential for foreign economic cooperation of the GTI member countries seems to be possible to assess using the complementarity index. This index is an indicator of the practicability of cooperation, and it allows to assess the extent of the commodity and sectoral differentiation of national producers and makes it possible to organize complementary technological and production ties. The higher the value of this index, the more countries can realize their benefits in trade through mutual compensation of needs based on trade specialization. From the point of view of foreign economic cooperation, this indicator characterizes the reserve of optimization of the national economic complex of each GTI member country and the possibility of increasing its efficiency.

Table 2. Recognition of the stages of crisis phenomena in foreign trade cooperation of GTI: the scale and intensity of signals, $\%$

\begin{tabular}{lll}
\hline Scale (S) & Intensity $(\mathrm{I})$ & Crisis stage \\
\hline $0-30$ & $0-30$ & None (green zone) \\
$30-50$ & $0-30$ & Potential (green zone) \\
$30-50$ & $30-50$ & Hidden nascent (green zone) \\
$50-60$ & $0-30$ & Hidden nascent (green zone) \\
$50-60$ & $30-50$ & Hidden developing (green area) \\
$50-60$ & $50-60$ & Hidden developing (yellow zone) \\
$60-70$ & $0-30$ & Hidden nascent (green zone) \\
$60-70$ & $30-50$ & Hidden developing (yellow zone) \\
$60-70$ & $50-60$ & Hidden progressive (yellow zone) \\
$60-70$ & $60-70$ & Hidden progressive (yellow zone) \\
$70-90$ & $0-30$ & Hidden developing (yellow zone) \\
$70-90$ & $30-50$ & Hidden progressive (yellow zone) \\
$70-90$ & $50-60$ & Hidden progressive (yellow zone) \\
$70-90$ & $60-70$ & Progressive turning into acute (red zone) \\
$70-90$ & $70-90$ & Progressive turning into acute (red zone) \\
$90-100$ & $0-30$ & Hidden developing (yellow zone) \\
$90-100$ & $30-50$ & Hidden progressive (yellow zone) \\
$90-100$ & $50-60$ & Hidden progressive (yellow zone) \\
$90-100$ & $60-70$ & Progressive turning into acute (red zone) \\
$90-100$ & $70-90$ & Sharp (red zone) \\
$90-100$ & $90-100$ & Sharp (red zone) \\
\hline
\end{tabular}

Source: Bayramov (2020) 


$$
S_{e j m k}=1-\frac{\sum_{i=1}^{n}\left|E_{i j}-M_{i k}\right|}{2}
$$

where $S_{\text {ejmk }}$ - complementarity index;

$j$ - exporter;

$k$-importer;

$i$ - goods;

$E_{i j}$ - part of goods $i$ in the total exports of country $j$ to the world market;

$M_{i k}$ - part of goods $i$ in the total import of country $k$ from the world market.

\section{Results and Discussion}

Over the past five years, the dynamics of foreign trade flows defined as a cargo base for transport projects within the GTI showed positive trends, with the exception of certain directions and time periods (Table 3). The increase in the final indicators was observed in all directions, except for the export of the Republic of Korea to China, Mongolia to Russia and the Republic of Korea. The average share of the GTI in the export of participating countries is more than $11 \%$.

Table 3. Dynamics of foreign trade cooperation of the GTI member countries, USD billion

\begin{tabular}{llllll}
\hline Direction & 2015 & 2016 & 2017 & 2018 & 2019 \\
\hline China-Republic of Korea & 101.47 & 94.66 & 102.83 & 109.03 & 110.98 \\
China-Russia & 34.81 & 37.51 & 43.15 & 48.01 & 49.48 \\
China-Mongolia & 1.57 & 0.99 & 1.26 & 1.65 & 1.83 \\
Republic of Korea-China & 137.14 & 124.43 & 142.12 & 162.16 & 136.21 \\
Republic of Korea-Russia & 4.69 & 4.77 & 6.91 & 7.32 & 7.78 \\
Republic of Korea-Mongolia & 0.25 & 0.21 & 0.23 & 0.31 & 0.29 \\
Mongolia-China & 3.90 & 3.88 & 5.27 & 6.51 & 6.77 \\
Mongolia-Russia & 0.08 & 0.06 & 0.07 & 0.09 & 0.07 \\
Mongolia-Republic of Korea & 0.07 & 0.01 & 0.01 & 0.02 & 0.03 \\
Russia-Republic of Korea & 13.09 & 10.03 & 12.35 & 17.83 & 16.36 \\
Russia-China & 27.31 & 28.02 & 38.92 & 56.04 & 56.79 \\
Russia-Mongolia & 1.08 & 0.90 & 1.33 & 1.61 & 1.73 \\
\hline
\end{tabular}

Source: Kampf, R., Majercak, P., \& Svagr, P. (2016)

The total share of GTI directions in the export of the Republic of Korea is almost $26.6 \%$, of which more than $25 \%$ falls on export flows to China and about $1.5 \%$ - to Russia. Note that the share of Russia has consistently increased over the period under review. Mongolia, as another GTI direction, has a fairly stable share, although its share in the total export of the Republic of Korea is insignificant (0.05\%). In absolute terms, the export of the Republic of Korea to China was characterized by multidirectional dynamics, with the value of 136.21 billion dollars at the end of the period under review (Kampf, R., Majercak, P., Svagr, P., 2016). The average growth rate at the level of $100.8 \%$ was caused by significant reductions in the value of export flows in 2016 (by 9.2\%) and in 2019 (almost 16\%), while in 20172018 , the growth was at the level of $14.1-14.2 \%$. According to the results of the period, the export from the Republic of Korea to China decreased by slightly less than $1 \%$. The export of the Republic of Korea to Russia as a GTI direction was characterized by an annual increase, and as a result the final figure reached $\$ 7.78$ billion, that is $65.9 \%$ higher than the level at the beginning of the period. The average growth rate was $114.7 \%$. From 2017 to 2019, the value of export flows from the Republic of Korea to Mongolia has steadily 
increased, although the absolute figure is insignificant. A 5.4\% reduction in 2019 led to the absolute value of exports at $\$ 0.29$ billion, which is still $18.2 \%$ higher than at the beginning of the period, although it is noticeable only at the hundredth level.

In 2019, the total share of GTI directions in Russian exports was $17.71 \%$, and it was the maximum value for the entire period. This stable dynamic is explained by the consistent increase in the share of China to $13.43 \%$ and Mongolia to $0.41 \%$. The Republic of Korea reduced its position in the export structure to $3.87 \%$, but this value is not the minimum for the period. According to the results of the period, the value of Russia's export flows to China reached $\$ 56.79$ billion, thereby increasing more than 2 times compared to the initial indicator. The dynamics of exports was characterized by an extremely positive trend, while a significant increase was recorded in $2017-2018$ - by $38.9-44.0 \%$. In other time periods, the increase was approximately from $1.5 \%$ to $2.5 \%$. Russian exports to the Republic of Korea also showed an increase in the period - by $24.9 \%$ from $\$ 13.09$ billion to $\$ 16.36$ billion. The average growth rate was at $121.7 \%$, the dynamics was characterized by being in the positive zone, for excluding 2017 (a 23.4\% decrease) and 2019 (an 8.3\% decrease). Since 2017, Russia's export flows to Mongolia have shown positive dynamics with an average growth rate of $114.9 \%$. As a result, the export value reached $\$ 1.73$ billion, that is $60 \%$ higher than at the beginning of the period (Nedeliakova, E., Nedeliak, I. et.al., 2014).

Chinese exports in the GTI directions are $6.5 \%$ in total, which is the maximum indicators for the period 2015-2019. The largest share among the GTI member countries in China's exports belongs to the Republic of Korea $-4.4 \%$, the share of Russia is about $2 \%$, less than $0.1 \%$ falls on Mongolia. At the end of the period, the value of China's export flows to the Republic of Korea increased by $9.4 \%$ to $\$ 110.98$ billion. Note that after a decrease in the indicator by almost $7 \%$ in 2016 , there was a stable increase at the level from $2 \%$ to $8 \%$ in subsequent years. China's exports to Russia were characterized by an annual average growth rate of $9.3 \%$. In absolute terms, the final figure was $\$ 49.48$ billion, which is $42.2 \%$ higher than the same indicator at the beginning of the period. Export flows to Mongolia showed stable positive dynamics after declining by almost $37 \%$ in 2017 , but their growth varied significantly - from $11.1 \%$ in 2019 to $30.6 \%$ in 2018 . In general, the final absolute value was at the level of $\$ 1.83$ billion - an increase over the period of $16.4 \%$.

The share of GTI directions in Mongolia's export flows is $90.1 \%$, while the average value for the period is $87.5 \%$. The largest share traditionally belongs to China - almost $89 \%$ at the end of 2019, the shares of Russia and the Republic of Korea in this structure are $0.9 \%$ and $0.4 \%$, respectively. At the end of the period, the value of Mongolia's exports increased only towards China - by almost $74 \%$ (to $\$ 6.77$ billion), which was preceded by a stable positive trend (an average increase of 15.7\%), except for an extremely insignificant reduction in 2017. Mongolia's exports to Russia decreased by $11.4 \%$, although due to the positive trend in $2017-$ 2018 , the average growth rate is at $100 \%$. In general, the absolute values of the indicators are insignificant $-\$ 0.07$ billion in 2019. An even more significant decline was observed in exports to the Republic of Korea - by $58.2 \%$ to the final figure of $\$ 0.03$ billion. At the same time, over the past three years, the value of exports has steadily increased. However, the 2017 decline by $87.2 \%$ and was not compensated.

The results of calculating the stability coefficient of foreign trade cooperation within the GTI (Table 4) indicate that the export of China to the Republic of Korea, Mongolia to China, Russia to Mongolia is characterized by a highly stable positive trend, while the rate of positive changes slows down with weak stability. A similar trend and the degree of its stability are typical for Russian exports to China. However, the rate of positive changes slows down with weak stability, as well as for Chinese exports to Mongolia, the Republic of Korea in Russia and Mongolia, while positive changes are increasing their rate with medium stability. China's exports to Russia are also highly stable and positive in their trend, but with a moderately stable deceleration. Russia's exports to the Republic of Korea are characterized 
by an average stability of the positive dynamics of absolute indicators, and the rate of these flows increases with a high degree of stability. Weak stability of dynamics was recorded for the exports of Mongolia to Russia and the Republic of Korea to China. Moreover, in the first case, an increase in the rate of positive changes with an average stability is observed, in the second - a slowdown in the rate with the same degree.

Table 4. Diagnostic matrix of stability of foreign trade cooperation within the GTI ("+" - positive dynamics, “-" - negative dynamics)

\begin{tabular}{|c|c|c|c|c|c|c|c|c|c|}
\hline \multirow{3}{*}{\multicolumn{2}{|c|}{$\begin{array}{l}\text { Stability of relative } \\
\text { indicators (growth } \\
\text { rates), stability of } \\
\text { rate }\end{array}$}} & \multicolumn{8}{|c|}{ Stability of absolute indicators, stability of the trend } \\
\hline & & \multicolumn{2}{|c|}{$\begin{array}{lll}\mathrm{K}< & < & 0.2, \\
\text { instability } & \end{array}$} & \multicolumn{2}{|c|}{$\begin{array}{l}0.2<\mathrm{K}<0.4 \text {, } \\
\text { weak stability }\end{array}$} & \multicolumn{2}{|c|}{$\begin{array}{l}0.4<\mathrm{K}<0.6 \text {, } \\
\text { medium } \\
\text { stability }\end{array}$} & \multicolumn{2}{|c|}{$\begin{array}{l}\mathrm{K}>0.6, \text { high } \\
\text { stability }\end{array}$} \\
\hline & & + & - & + & - & + & - & + & - \\
\hline \multirow{2}{*}{$\begin{array}{l}\mathrm{K}<0.2, \\
\text { instability }\end{array}$} & + & - & - & - & - & - & - & - & - \\
\hline & - & - & - & - & - & - & - & - & - \\
\hline \multirow[t]{2}{*}{$\begin{array}{l}0.2<\mathrm{K}<0.4 \text {, } \\
\text { weak stability }\end{array}$} & + & - & - & - & - & - & & $\begin{array}{l}\text { China-Korea, } \\
\text { Mongolia- } \\
\text { China, } \\
\text { Russia- } \\
\text { Mongolia } \\
\end{array}$ & - \\
\hline & - & - & - & - & - & - & - & Russia-China & - \\
\hline \multirow[t]{2}{*}{$\begin{array}{l}0.4<\mathrm{K}<0.6, \\
\text { medium } \\
\text { stability }\end{array}$} & + & $\begin{array}{l}\text { Mongolia- } \\
\text { Korea }\end{array}$ & - & $\begin{array}{l}\text { Mongolia- } \\
\text { Russia }\end{array}$ & - & - & - & $\begin{array}{l}\text { China- } \\
\text { Mongolia, } \\
\text { Korea-Russia, } \\
\text { Korea- } \\
\text { Mongolia }\end{array}$ & - \\
\hline & - & - & - & Korea-China & - & - & - & China-Russia & - \\
\hline \multirow[t]{2}{*}{$\begin{array}{l}\mathrm{K}>0.6 \text {, high } \\
\text { stability }\end{array}$} & + & - & - & - & - & $\begin{array}{l}\text { Russia- } \\
\text { Korea }\end{array}$ & - & - & - \\
\hline & - & - & - & - & - & - & - & - & - \\
\hline
\end{tabular}

Source: Kampf, R., Majercak, P., \& Svagr, P. (2016)

Based on the presented calculation method, the indicators of the scale and intensity of crisis signals are less than $10 \%$, which indicates the absence of crisis phenomena in foreign trade cooperation between the GTI member countries, and the zone of its development is green. In other words, the stability of trends and the rate of development of foreign trade cooperation ensure the highest level of security so as not to go into crisis stages, even considering the unfavorable situation in the world economy. The assessment of the feasibility of the development and implementation of transport projects for various long-term scenarios should be associated with the presented assessment and the security zone for the development of foreign trade cooperation identified and based on its results, thus this cooperation reflects the key areas those provide the cargo base of GTI projects (Nedeliakova, E., Sekulova, J., et.al., 2014).

On the other hand, in addition to the stability of the existing foreign trade flows within the GTI, a fundamental point is to identify the potential for cooperation between the participating countries, i.e., in fact, the expediency of these flows. The complementarity indexes were calculated for pairs of countries (Table 5).

Table 5. Indices of complementarity of foreign economic cooperation within the GTI

\begin{tabular}{lllll}
\hline & \multicolumn{2}{l}{ Importer } & & \\
\cline { 2 - 5 } Exporter & Russia & Republic of Korea & China & Mongolia \\
\hline Russia & - & 0.34 & 0.35 & 0.48 \\
\hline
\end{tabular}




\begin{tabular}{lllll}
\hline Republic of Korea & 0.57 & - & 0.63 & 0.67 \\
China & 0.69 & 0.64 & - & 0.75 \\
Mongolia & 0.10 & 0.11 & 0.28 & - \\
\hline
\end{tabular}

Source: own research

The highest complementarity index reflects China's export flows to Mongolia and Russia, as well as the Republic of Korea to Mongolia. Mongolia's exports in all directions within the GTI are characterized by the least complementarity. The average value of the complementarity index within the GTI is about $0.5(50 \%)$, which indicates not only the potential of foreign economic cooperation for member countries, but also the need to take measures to further intensifying, including foreign trade transport services improvement.

The principled character of a comprehensive and timely study of the issues of substantiation of various transport projects is explained by the fact that transport is the most significant and feasible area of cooperation within the GTI. Note is taken that the original Tumen project (1990) was mainly "a transport hub project". As for the GTI, several transport problems were solved in the first few years, including the implementation of a project for an international ferry service between the ports of Zarubino (Russia), Sokcho (Republic of Korea) and Niigata (Japan).

Currently, there are several key transport projects within the GTI:

- creation of vehicle ferry system in North-East Asia;

- modernization of the port of Zarubino;

- completion of the construction of the Makhalino (Kraskino) - Hunchun railway line and the beginning of a full-fledged transport interaction along this route;

- a road and harbor construction project at China and North Korea border.

Note that some of these projects are not only not implemented, but are not planned for implementation yet due to a number of reasons.

In accordance with the Seoul Declaration (December 16, 2020), the development of the GTI transport sector involves ensuring the smooth operation of transport corridors in Northeast Asia by harmonizing and simplifying border crossing formalities and removing existing barriers for intermodal transit traffic. Note that the Russian side just focuses on transit routes, which can become the basis for the implementation of the strategy of transport corridors within the GTI. Indeed, the use of Russia's transit potential may become a fundamentally new area of transport cooperation. We are talking about improving the Eurasian transport corridors and routes (modernization of the Trans-Siberian railway, the Baikal-Amur railway, Pacific ports, etc.), the development of new routes providing access from Europe to the ports of the Russian Far East and further to the countries of Northeast Asia (Jerabek, K., Majercak, P. et al, 2016).

However, taking into account the prevailing trends in Europe-Asia transportation, it is not entirely correct to make the implementation of GTI transport projects dependent on prospective transit freight flows. At first, it is necessary to concentrate on the transport support of foreign trade flows directly between the GTI member countries. The results of the assessment of foreign trade cooperation indicate a positive trend in all areas, while the degree of its stability varies from weak to high. In the overwhelming number of directions, both a high stability of the trend and a high stability of the increase in the rate of positive changes are observed. All this testifies to the high level of foreign trade cooperation within the GTI, which, from these positions, is developing in a safe zone with no signs of crisis phenomena. Besides, the member countries have the potential to build up foreign trade relations, allowing them to complement technological production ties in accordance with the commodity diversification of exports and imports.

Consequently, improving the transport and logistics infrastructure in the Tumen region is of a vital necessity in accordance with the existing foreign economic relations between the 
GTI member countries, their current state, and prospects for expansion. The existing cargo base can influence the efficiency of transport projects in the region, and on the other hand, the advanced development of the transport sector can become a real trigger for economic cooperation and the transformation of GTI into an independent intergovernmental organization.

\section{Conclusion}

In general, it can be concluded that the GTI member countries have significantly increased their potential for intergovernmental cooperation to promote trade relations in the region. Foreign economic cooperation within the GTI is obviously the basis for interaction in various fields, especially in transport. On the other hand, the development of some transport corridors and improvements in border crossing processes, transshipment points, etc. are made directly dependent on their congestion with foreign trade flows. Consequently, the development and feasibility of implementing transport projects of GTI should be based on the potential of foreign economic cooperation between its member countries.

Based on the results of the assessment of foreign trade flows between the member countries, that forms the current and potential cargo base of transport projects, it was concluded not only about a high degree of stability and potential of foreign economic cooperation, but also about the need of extra measures for its further intensifying, including foreign trade transport services improvement.

In this context, transport projects should be focused on improving transport and logistics infrastructure, simplifying border-crossing procedures, and developing improved types of transport and logistics services and technologies. There is a need to implement the tasks of transport connectivity through existing transport corridors, which requires an improvement in their performance characteristics, as well as the construction of new corridors. For more efficient services in foreign trade flows, and transit in the future, it is necessary to develop interstate agreements in the field of transport, the implementation of those would benefit to all GTI member countries. The transport corridor management system is also of fundamental importance, including coordinating organizations created by the member countries together.

\section{Acknowledgements}

This paper is output of scientific project $057 Z \check{Z}$-4/2021 Innovative approaches in the system of teaching logistics with a focus on the creation of logistics networks in pandemic conditions.

\section{References}

1. Bayramov, V., Rustamli, N., \& Abbas, G. (2020). Collateral damage: The Western sanctions on Russia and the evaluation of implications for Russia's post-communist neighbourhood. International Economics, 162, 92-109.

2. Fleisher, B. M., \& Zhang, X. (2021). China economic review 30 years.

3. Foo, N., Lean, H. H., \& Salim, R. (2020). The impact of China's one belt one road initiative on international trade in the ASEAN region. The North American Journal of Economics and Finance, 54, 101089.

4. He, L. Y., Lin, X., \& Zhang, Z. (2020). The impact of de-globalization on China's economic transformation: Evidence from manufacturing export. Journal of Policy Modeling, 42(3), 628-660. 
5. Cheng, C. H. J. (2017). Effects of foreign and domestic economic policy uncertainty shocks on South Korea. Journal of Asian Economics, 51, 1-11.

6. Chu, A. M., Lv, Z., Wagner, N. F., \& Wong, W. K. (2020). Linear and nonlinear growth determinants: The case of Mongolia and its connection to China. Emerging Markets Review, 43, 100693.

7. Jerabek, K., Majercak, P., Kliestik, T., \& Valaskova, K. (2016). Application of Clark and Wright' $\mathrm{s}$ savings algorithm model to solve routing problem in supply logistics. NAŠE MORE: znanstveni časopis za more i pomorstvo, 63(3 Special Issue), 115-119.

8. Kampf, R., Majercak, P., \& Svagr, P. (2016). Application of break-even point analysis. NAŠE MORE: znanstveni časopis za more i pomorstvo, 63(3 Special Issue), 126-128.

9. Lall, S. V., \& Lebrand, M. (2020). Who wins, who loses? Understanding the spatially differentiated effects of the belt and road initiative. Journal of Development Economics, 146, 102496.

10. Lim, E. S., \& Breuer, J. B. (2019). Free trade agreements and market integration: Evidence from South Korea. Journal of International Money and Finance, 90, 241-256.

11. Lu, S., Shen, J. H., Li, W., \& Zhang, J. (2020). A theory of economic development and dynamics of Chinese economy. Economic Modelling, 86, 69-87

12. Majercak, P., Kliestik, T. et.al. (2013). System Approach of Logistic Costs Optimization Solution in Supply Chain. Nase more, 60 (5-6).

13. Magazzino, C., \& Mele, M. (2020). On the relationship between transportation infrastructure and economic development in China. Research in Transportation Economics, 100947.

14. Mitsek, S. A. (2018). Econometric model of Russian Federation: analysis and forecasts for 2018-2019. IFAC-PapersOnLine, 51(32), 395-400.

15. Nedeliakova, E., Sekulova, J., Nedeliak, I., \& Majercak, P. (2014). Safety of Level Crossings from Society-Wide Perspective. Transport Means, 23-24.

16. Nedeliakova, E., Nedeliak, I., \& Majercak, P. (2014). Research of services quality after the end of transportation in railway freight transport. ICMIBI, Bangkok, Thailand.

17. Nekhoroshkov, V., Aroshidze, A., \& Nekhoroshkov, E. (2021). Transport Support of Europe-Asia Trade: Structural Shifts. Transportation Research Procedia, 54, 182-190.

18. Ono, S. (2017). Financial development and economic growth nexus in Russia. Russian Journal of Economics, 3(3), 321-332.

19. Sim, S. G., \& Yoo, D. (2018). A quantitative study on endogenous formation of comparative advantage in South Korea. International Review of Economics \& Finance, 53, 71-87.

20. Thorbecke, W. (2019). East Asian value chains, exchange rates, and regional exchange rate arrangements. Journal of asian economics, 65, 101132.

21. Voskoboynikov, I. B. (2017). Sources of long run economic growth in Russia before and after the global financial crisis. Russian Journal of Economics, 3(4), 348-365. 